Paraplegia 21 (1983) 264-265

(C) 1983 International Medical Society of Paraplegia

\title{
ADDENDUM
}

\section{Post-traumatic Syringomyelia}

By J. D. Vernon, J. R. Silver and A. Ohry

Volume 20, Number 6. Pages 339-364

The authors regret that these case reports were omitted from the above paper.

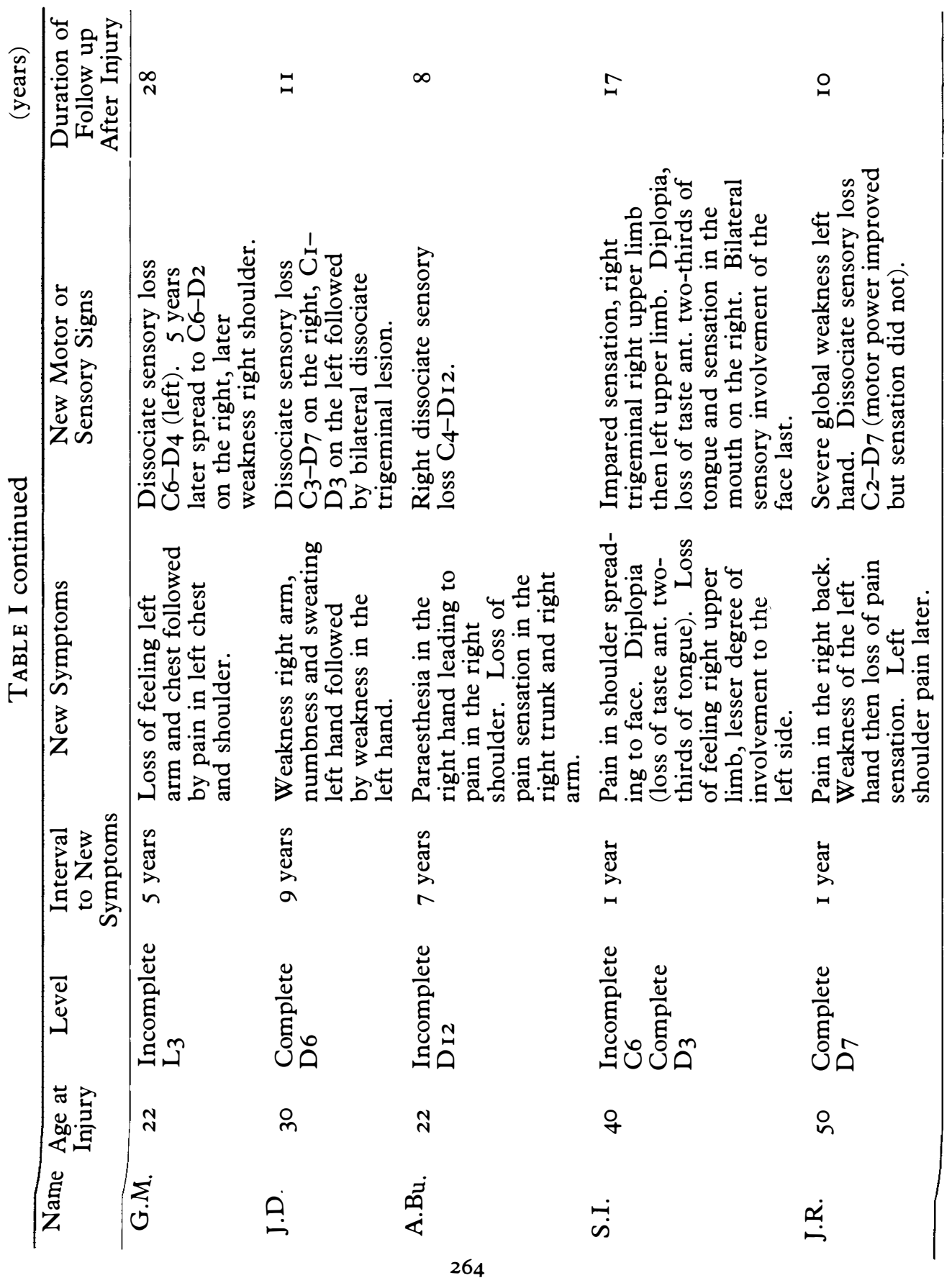


The following corrections to this paper should also be noted.

On page 358 in the paragraph beginning 'In D.K., an incomplete paraplegic....' $\mathrm{C}_{2}$ should read Di2.

On page $36 \mathrm{I}$ the last sentence of the first paragraph should read ' $\ldots$... with a cyst in the medulla (Fig. 5). Another case is S.I., see Table I and Figures 6 and 7.' 